\title{
Psychoanalytic Understanding of Repeated In-Vitro Fertilization Trials, Failures, and Repetition Compulsion
}

\author{
Mali Mann, M.D* \\ Department of Psychiatry and Behavioral Sciences, Stanford University Medical Center, 550 Hamilton Ave, Suite 210, Palo Alto, CA, United States
}

${ }^{*}$ Correspondence author: Mali Mann M.D, Department of Psychiatry and Behavioral Sciences, Stanford University Medical Center, 550 Hamilton Ave, Suite 210 , Palo Alto, CA 94301, United States; Tel: 650-325-8762; E-mail: mannm@stanford.edu

Received: August 09, 2018; Accepted: August 23, 2018; Published: September 05, 2018;

\section{Case Report}

Recent advances in reproductive technology and the increased use of techniques based upon it have created a need for psychoanalytic thinking and understanding of the psychological implications of invitro fertilization (IVF) and other similar procedures. The recent and rapid advances in medical technologies confront us with the mandate to understand their complex impact on women and their children. As a physician and psychoanalyst, I became aware of my patients' trouble accepting their infertility after drawn out, continued attempts to have their own children. The acceptance of their failure in conceiving is more of a challenge for some patients than others, although there can never be a final acceptance. The denial of their failure as a couple to conceive can become a long process with unfinished mourning throughout their life cycle.

The two cases in this paper in particular illustrate how infertility traumata were re-experienced. The unconscious self-induced traumatization resulted from the compulsion to repeat an earlier repressed trauma. Freud inferred the existence of motivation beyond the pleasure principle. In 1919 he postulated "the principle of Repetition Compulsion the unconscious mind, based upon instinctual activity and probably inherent in the very nature of the instincts a principle powerful enough to overrule the pleasure-principle." Building on his 1914 article Recollecting, Repeating and Working Through, Freud highlighted how the "patient cannot remember the whole of what is repressed in him, and is obliged to repeat the repressed material as a contemporary experience instead of...remembering it as something belonging to the past: a compulsion to repeat."

Those individuals who can better accept their infertility without significant psychological complication resort to other methods of becoming parents to fulfill their life-long expectation. Some may take an alternative step and adopt someone else's child. Some infertile individuals whose infertility is related to their advanced age use alternative procedures such as In-Vitro Fertilization (IVF). In today's world, many women want to establish themselves in their careers and choose to postpone reproductive goals until later. When they face reproductive failure, they become extremely anxious, especially when the biological clock is ticking away faster and faster. The narcissistic injury is deep and debases their belief system about selfrepresentation and their body image. Women are affected profoundly by infertility failure. They carry with them the identification linkage with their primary pre-oedipal maternal object, wanting to become a parent. We see clinically girls who play mother roles in fantasy. Once a woman's pregnancy wishes are frustrated, the denial of an infertile self-image could potentially lead to crisis. The way in which these women react to the trauma of their infertility will determine a number of factors, including how they choose to use a donor egg, donor sperm, or surrogate mother. The character of their traumatic experience also depends upon the process of deciding who will donate their egg, their sperm, or their womb. Though the reasoning varies among theories, experts agree that the ability to become a mother is essential to believing that one is viable as a woman. Freud [1] made passing reference to the subject of human reproduction and pregnancy. The primacy of sexuality in human life for Freud is reflected in his belief that the wish for a child in the woman represents the symbolic substitution for the missing penis; a wish for reparation and completion.

Helene Deutsch [2] questioned the reparative function of the woman procreative life. She made it clear that the woman's urge to become pregnant and bear a child represents the essentially feminine quality of receptiveness, a bio-physiological concept, the bedrock of femininity.

Benedek and Bibring et al. [3,4] , pioneers in the study of women's reproductive drive, saw pregnancy as a developmental crisis, and subsequent writers seem to accept this view [5].

In severely traumatized women the wish to be pregnant is not necessarily connected to the wish for a child, as seen by Pines [6]. Pregnancy, instead, is simply seen as an effort to repair the narcissistic injury of early life.

Pines elaborated on mother-daughter relationship as the locus of psychic conflict in women who abort habitually. Pre-oedipal dynamics were discussed and identified by Lester \& Notman [5,7] as causing anxieties during the early stages of pregnancy.

In her paper "Infertility in the Age of Technology" [8] Zallusky highlighted the effect of infertility on analytic process. She elaborates on the permeability of the boundaries between analyst and patient and between fantasy and action in psychoanalytic work with women who are infertile and resort to Assisted Reproductive Technology (ART). The immense stress of infertility can trigger regressions to earlier stages 
of psychological development. Intense feelings of envy and shame felt currently, conflict with their roots in childhood, bringing about a disturbance to the person's sense of self-identity. As Freud stated, the ego "is first and foremost a body ego" [9]. The earliest way in which we know ourselves is through our body. Kite (2009) emphasized the importance of keeping the emotional reality of the patient in view in a panel on "Current Perspective on Infertility," in which the motivations for childbearing were discussed in relation to ART.

The entry of a third person-the doctor-into the sexual relationship, as if into the primal scene, is another theme in some of the literature. Also in the context of surrogate mothers and/or sperm donation, Ehrensaft [10] described the feelings and fantasies of parents in relation to having another, outside party involved in conception. She described a stirring up of fantasies of a ménage a trois. She observed that the egg donation or the surrogate could stir up fantasies of the other. Thinking of the sperm as sperm may be defensive against thinking of the sperm as coming from another whole person. Ehrensaft also pointed out the importance of telling children about their origins. Coming to terms with infertility or mourning can manifest as a problem not only for women, but also for both partners as well as primarily for men.

\section{In-Vitro Fertilization}

In-vitro fertilization means "fertilization under glass," ie: in a test tube. IVF is a technique for removing eggs from a woman, fertilizing them outside her body, and placing the fertilized egg, or embryo, directly into the uterus. All IVF procedures have four steps: ovarian stimulation, egg retrieval, fertilization, and embryo transfer.

Overcoming infertility was unimaginable just a generation or two ago. Since then, scientists have devised a way to remove the sperms and eggs and combine them. Eggs are fertilized, and then frozen for future use; sperm strength can be boosted; and even women who lack ovaries may find themselves pregnant. These procedures arouse much curiosity within the general public and within the broad community of infertility and mental health experts.

The first "test tube baby," was born in 1978. Louise Brown was the first child to be conceived by in-vitro fertilization and was delivered after a full-term pregnancy. In the few years since, IVF has become an important element in the vocabulary of infertility. It has become the cutting edge of modern reproductive treatment and research. Invitro fertilization requires intact fecundity, normal production of ova. Today, a number of women in mid- to late thirties and early forties, in spite of their intense desire to conceive, remain infertile. Fecundity is intact in many of these subjects, and advances in reproductive technology makes it possible to overcome infertility in some of these cases. New ground continues to be broken as research continues.

Regardless of the cause of infertility, the treatment that leads to the highest pregnancy rate per cycle is in-vitro fertilization. Since its inception in 1978, there has been a remarkable increase in the numbers of IVF cycles worldwide. Approximately one in fifty births in Sweden, one in sixty births in Australia, and one in $80-100$ births in the United States now result from IVF. In 2003, more than 100,000 IVF cycles were reported from 399 clinics in the United States, resulting in the birth of more than 48,000 babies. IVF is now the treatment that leads to the highest pregnancy rate per cycle (New England Journal of Medicine, 2007).

Egg donation was introduced in the 1980s, increasing the possibility of pregnancy and child bearing to many women. Many of the women receiving these donations were older and had delayed child bearing for reasons such as establishing careers, personal conflict, and ambivalent feeling about becoming mothers. These women, and those who had illnesses the treatment of which affected their fertility, were then able to have children. Still, egg donation brought up a great deal of controversy. In addition to ethical dilemma, egg donation presents issues such as parental identity confusion and compromised sense of social group belongingness. I have encountered many clinical examples of this but expounding upon them would be beyond the scope of this paper.

The use of surrogates-women who carry a pregnancy for another individual or couple - generates further possibilities for women unable to conceive. The baby can have the genetic identity of the couple -that is, the ovum can be obtained from the woman in the couple and be fertilized by the man's sperm and then implanted in the woman who has agreed to be the surrogate - or the surrogate can supply the ovum and the sperm can be the husband's or come from a donor. This has made having a genetically related baby possible for gay couples, as well for women who for some reason, such as repeated pregnancy loss, cannot carry a baby to term but have viable ova. It is possible to freeze sperm, eggs, or embryos for later use.

Implanting more than one embryo increases the likelihood of having a viable pregnancy. It also increases the likelihood of multiple births, which carries greater risks. The decision to reduce one or more embryos in the lieu of multiple implantations is a difficult one. In this article, I do not focus on the traumatic effect of infertility. Instead I discuss the use of multiple IVF trials despite repeated failures. One of the cases I discuss, for example, presents a serious narcissistic injury and disappointment at the discovery of infertility, which in turn affected the decision and the process of assisted reproductive technology. The delay in decision-making created medical risks during this woman's pregnancies. She insisted on going through a second pregnancy using her own uterus to carry a fetus that came from the union of her husband's sperm and an egg donor, her niece.

\section{Unexplained Infertility}

No matter how sophisticated the technique used to combat infertility, there are cases in which a woman remains infertile. Some causes of infertility remain beyond our understanding, even in these days of enlightened biological technology and modern-day high-tech reproductive procedures. These as-yet unsolved mysteries are very frustrating to those trying to understand why some people can conceive and others cannot. Unexplained infertility is a "diagnosis of exclusion." This means that all other known diagnoses must be eliminated before the infertility can fairly be called "unexplained." Making claims about the causality of infertility and the concept of psychogenic infertility is not a useful argument for us as psychoanalysts. Conscious and unconscious hostility toward a defective male sibling [11], and a woman's unconscious repudiated femininity or motherhood can be important dynamics. However, there are couples who are able to 
conceive naturally in spite of similar dynamics. We need to be careful not to confuse the correlational data with causality.

In recent years, infertility treatment has undergone a genuine revolution, which has raised the possibilities for empirical treatment. Today's infertility treatment is referred to as "assisted reproductive technology;" most simply stated, ART represents the joining of a hormonal therapy with a form of artificial insemination. ART is most commonly represented by intra-uterine insemination, IVF, and IVF's variations.

\section{Case \# 1: Jean}

Jean, a married forty-eight year old woman, came to see me for analysis after a hiatus in her psychotherapy. During her previous years of treatment with me when she was in her early forties, she saw me twice a week. She worked in a demanding professional field and did not know why she could not conceive. She decided to wait and try natural methods to get pregnant. She made many attempts over a long period of time to conceive without any success. Jean's professional life was a trying and challenging one and kept her very occupied to the point that she lost track of passing years. She did take pride in her work and wanted to appear to her colleagues as "perfect" and "flawless."

Jean's inability to conceive was very difficult for her to accept, since she thought nothing was physically wrong with her. Male factors for infertility were ruled out. It meant to her that she was defective. Jean's husband, who was in a similar professional field, was very supportive of her; and he was willing to adopt or even be childless if Jean chose not to have any children. Jean was shame ridden about being defective and not being able to have children as her mother did. She felt intense envy toward her mother and especially her sister who was five years her senior and had one son. Her envy of pregnant women was very intense, making her angry when she encountered pregnant women. Jean came from a deprived background both emotionally and financially. She had memories of not having food and going hungry to school. She was not sure if she was conceived out of wedlock. She believed her sister was so conceived, and in her fantasy she thought her father never married her mother.

Jean's brother was born when she was eight years old. She remembers her parents were overjoyed because they finally had a son after so many years. Jean devalued her mother for her emotional detachment, but would also show guilty feelings for her rage toward her mother. In her day-to-day interactions, Jean lacked emotional responsiveness. She tried hard to be friendly with her colleagues, as long as they praised her at work. She had many superficial friendships, but she could not go beyond the surface level in relationships. At the beginning of our work, this patient had immediate realistic concerns about dying before she could fulfill her dream of becoming a mother. Her resistance to becoming fully involved in the transference was expressed in the form of overvaluing her job, dealing with life and death issues, and considering her analysis "just talking," a process in which "not much important action was happening."

Jean related that no matter how much insight she would gain through our work, she still needed to take action by hurrying to have children from her own eggs before it was too late. She wanted her gynecologist to give her strong fertility medication like Lupron and other infertility medications to make her fertile. She went through multiple IVF procedures during this period. Each time they harvested her eggs, she would come in and boast about how many of her own eggs they were able to harvest. She turned a blind eye to the factual comments that several experts made to her about her age factor, which made her eggs unsuitable for IVF. She knew that the probability of getting a viable embryo out of her ovum was very low. She vehemently defended her decision and said, "I just do not want to borrow another woman's eggs."

"Borrowing" another woman's eggs would mean that Jean was inferior to egg donors. After her husband suggested that perhaps they could consider an anonymous donor, though, she assented. Yet she waffled. If she could only find an anonymous donor from another country, perhaps she would follow through. In the end, Jean turned away from making the decision.

At this stage of our work, she was obsessed with going through many cycles of IVFs without showing much interest in exploring the meaning of her desperate actions. Only after many failures in conceiving did Jean begin to wonder why she could not get pregnant. She thought she was either being punished or she was just flawed. Her almost total absence of fantasy material toward me gradually gave way to being intensively curious about my personal life after she inadvertently learned that I had a daughter. Having found out through a friend who attended a fund-raising event where I was participating with my daughter, Jean imagined that I must be an attentive mother myself and not like her own mother who was aloof and detached. She would use technical terms to show me that she was psychologically minded and a well-read, intellectual woman. However, she would mispronounce or misuse words and quickly apologize to me for not having used the word accurately.

Jean would come to her sessions punctually, and she would get anxious when I took a break for a holiday or professional travel. She worried that I would never come back and that some disaster would separate us forever.

Gradually, the intense fear of her rage and somatic complaints gave way to uncovering the meaning of her dread over anything emotionally valuable in her life. She had intense envy of me as her analyst, and in fantasy wanted to exchange my rich and fulfilling life as a mother for her own barren existence.

In one of our sessions, after complaining that she had spent so many years of life in analysis without much change in her grief over being flawed (she still believed she was flawed), she agreed with my comment that I, too, must have failed her not to have given her the wisdom of my knowledge and experience; like her mother I, too, have given birth to a barren analytic child who was infertile. She acknowledged that although she agreed with much of what I said, she still had not given up on going through yet another IVF trial at her age. She was sure I could be not happy with her inability to conceive and that I would interpret it as if we both had failed.

Jean's conflict around unconscious envy of me emerged as an expression of hatred and distrust of her mother. Her sense of competitiveness also emerged as she wished to have a sense of triumph 
instead of missed opportunities. Her denial of reality regarding her advanced age for a successful IVF outcome continued to take the center stage of our analytic work. Jean continued to seek the creation of a baby from her own eggs fertilized by her husband's sperm. After seven trials without any success, she regretted putting herself through such vigorous procedures for a woman her age. She became more interested in the meaning of her loss. Finally she had to face it and go through the grief stage. She realized that she could no longer hold on to her dream.

At the end Jean realized that she could neither have a genetically related child, nor could she accept another woman's egg. After all, she could not picture herself as a nurturing mother, and she concluded that it may be for the best not to become a mother. She could not be like her own fertile mother and had to accept the reality of growing old. Finally, she was able to face her ambivalence. Jean could learn to be more nurturing to the vulnerable part of herself.

At this point, the memory of her brother's birth came up and her rivalry with him became a central theme in our work. The following is an example of how Jean characterized her envy:

Patient: I have all these mean thoughts and I feel really bad.

Analyst: Carrying the mean thoughts makes you feel guilt.

P: It is very harmful to be occupied with them.

A: In our last hour you mentioned how hard it was to deal with jealousy at your brother's birth.

P: Yes, Mom was mad at me for being jealous of my brother. I am never good enough. Other people have talents and value, not me. There is this other part of me that is irrational and unkind.

There was always a feeling about my chance of getting pregnant with IVFs. How many attempts I made to give birth was like pushing a pickle through a straw. How many mean thoughts I would have! I am trying to make sense of these feelings. I am flawed, but I want to be saintly and have power to make these women lose their babies or relinquish them when they are born. I have those mean, evil thoughts. I am torn again all the time.

It ran through my mind that if I had special power, the technology would have worked for me. I would have gotten pregnant by now. Technology is amazing and works for others, but not me. There is a zinger in that. I did not want to have a flawed child, so maybe it was for the best that I did not get pregnant.

After many years of attempts, Jean was in a place to make a decision to adopt a one-year-old girl from China. This was a reasonable compromise for her after so many years of struggling with her desire to have her own biological child. Our analytical work had helped her to work through her early mother-daughter and Oedipal conflicts.

\section{Case\#2: Fran}

Fran was a forty-eight year-old lawyer who came to see me because of depressive symptoms and romantic disinterest in her husband. She was hurt and angry because her husband became emotionally involved with a woman at his work. She thought her husband had become detached because she was putting all of her effort into using reproductive technology to get pregnant.

Before her current marriage, she had been briefly married to a man who was very critical of her weight even though she was a woman of normal weight. They divorced after one year. She remarried at age forty after four years of a long-distance relationship with the man who became her husband. Her husband is an architect whom she met while she attended law school. Their sexual attraction and their individual interests in sexual activity diminished over time until it became nonexistent.

Fran was interested in having children and tried without success to get pregnant in the earlier years of her marriage. She and her husband went through a reproductive/fertility work up and did intra-uterine insemination without success. In the same year, it was discovered that her uterus had three large myoma. She underwent a myomectomy and then tried to get pregnant naturally. After many months without success, she went through six IVF procedures. Each time, Fran repeated the cycle of overstimulation of the ovaries, harvesting the eggs, in-vitro fertilization, and freezing of the viable embryos. She would become very hopeful and when the transfer failed, she would come to her sessions, crying in silence and going through another cycle of unfinished grief work. Fran then quickly bounced back and wanted to try IVF again. Her denial about the loss of her youth, wanting to remain a young fertile woman forever, was unshakable, and her sense of omnipotence governed her fantasy.

Fran came from a family of eight children. Her father was a professor and her mother a nurse. After the first three children became school age, her mother decided to have a second set of five children. Fran is the eldest of the second set. Fran's father was overcritical and was frequently away traveling. Her mother was nurturing to the younger children, but the older ones were neglected. Fran had to take care of her younger siblings and did not have much private time for herself. She grew angrier each time her mother got pregnant. Her mother's fertility was the topic of Fran's conversations with her friends and in her therapy. Fran's conflict about motherhood was significant during the early years of her marriage. There were psychological as well as physical factors in her infertility that interfered with her becoming pregnant. She dis-identified with her mother who was "fruitful and multiplied."

As time progressed, Fran became aware of time's passage and questioned her childlessness. She became anxious and rushed to remedy her infertility by choosing to become a mother despite her inability to conceive naturally. Fran was influenced by unconscious psychological factors. Her unconscious repudiation of her femininity played an important role in her difficulty conceiving.

During her psychoanalytic treatment, Fran's developmental achievement of greater autonomy helped her "own" her femininity more fully. This enabled her to see herself more as a mature woman who needed to embark on the motherhood phase of her life despite her advanced years.

Fran and her husband tried to get pregnant for over ten years. She was almost fifty when she went through her first IVF. Her doctor said 
the chance of success was very slim, but she wanted to go through with it anyway. When it failed, she became depressed and had to deal with the loss of a dream to have a child with her own egg. She was struggling with her own sense of omnipotence - with issues of creating life in an ambivalent way, destroying life via denial of the reality of her advanced age. Through our analytic work, she gradually became aware of her intense repetition compulsion, accepting the reality of her aging ovum and ushering her body into the menopause phase of life. With reluctance, Fran considered going through a search for an egg donor. She decided to ask her niece to become her donor. Her niece was a young woman in her early twenties. Her niece agreed to go through the procedure for Fran with Fran's husband's sperm.

The IVF was successful and the healthy fetus was implanted in Fran's uterus. The clinic kept three more embryos for possible future pregnancies. Fran's pregnancy was normal and her delivery uneventful. When her baby girl was born, Fran brought her to show me in my office. The girl had faint resemblance to her mother and Fran admitted that she looked like her niece more than her. She was thankful that her daughter was physically healthy.

This case shows a happy ending in certain respects and yet, there are many unanswered question about Fran's family dynamics. What will happen when the child asks where she came from? When the little girl became a school-aged child, Fran was not ready to disclose the reality of her origin. She is working in treatment to understand the underlying meaning of her decision of keeping it secret despite the fact that the rest of her family knows the child's origins.

\section{Discussion}

The two cases I described have a few psychological factors in common. Both women started rather late in their reproductive years to get pregnant. Their denials of their advanced age factor motivated both women to resort to repeated IVF trials without success. Both women had trouble accepting their infertility and insisted on having their own biological children. Jean felt deficient and deprived. She felt it was her right to have a baby. She was envious of her mother, sister, and sister-in-law's abilities to have their own children, and she wondered why not her. Jean was told her eggs may be defective, and her doctor advised her to use an egg donor. She was in despair and felt envious of her mother who did not have to go through a fertility work up. Jean attributed her difficulty conceiving to her mother's belief that she could not carry a baby because of her delicate body frame. After all, her mother's prophesy must have come true. At last Jean faced her infertility while she was going through her analytical work with me. With Fran, once her pregnancy wishes were frustrated, the denial of her infertile self-image pushed her to a potential crisis level. Her repetition compulsion is related to her unconscious envy of her mother who was "fruitful and multiplied," having eight children, unlike her. After multiple trials, Fran accepted that the only way she could become pregnant was through a donor egg. She has not fully thought through the pros and cons of selecting a family member as her egg donor.

Both patients' narcissistic injuries were deep, and this debased their belief system about their self-representations and their body images. They carry with them the identificatory linkage with their primary pre-oedipal maternal object, wanting to become parents. As we see clinically, girls play mother roles in fantasy. In reality once their wishes are unfulfilled, the desire to get a different result than the one they face reaches a critical level. These conflicts propel them to try repeatedly to master the traumatic impact of their infertility.

Both cases suffered from the trauma of having to go through reproductive technology. Jean took an alternative step and adopted a child, while Fran got pregnant with a donor egg. Freud introduced the concept of repetition compulsion in Remembering, Repeating and Working-Through and Beyond the Pleasure Principle [12,13]. These essays marked a major turning point in Freud's theoretical approach. Previously, he had attributed most human behavior to the sexual instinct (libido). He went "beyond" the simple pleasure principle, developing his theory of drives with the addition of death drive (referred to "Thanatos").

Freud examined the relationship between repetition compulsion and the pleasure principle. Although compulsive behaviors evidently satisfied some sort of drive, they were a source of direct un-pleasure. Somehow, "no lesson has been learnt from the old experience of these activities having led only to un-pleasure. In spite of that, they are repeated, under pressure of a compulsion." Freud concluded that the human psyche includes a compulsion to repeat that is independent of the pleasure principle.

In my clinical experiences working with a small group of women who have tried using IVF multiple times without any success, I saw clear evidence that unconsciously they resort to repeating a selfinduced traumatic event. A compulsion to repeat was evident in my analytical work with women who went through multiple IVFs without a successful outcome.

One of the important factors in Jean's case - repeating the use of procedure - illustrated her attempt to repair her early childhood neglect and abandonment. What is particular in Jean's case is her nonchalant attitude about the doctor's repeated warnings against using her aged eggs. Her denial was persistent, yet through our work she could finally face the reality of her infertility. Jean's fertility process required her to be away from her analysis for a prolonged period. Though on one level this was a matter of time, on another it was psychological; the reason she needed to be away was as a defense against intimacy with her analyst. One might think of her transference as a particular form of unconscious communication as appears in the projective identification process. She was abandoning me to fulfill her very important procreative goal-- leaving a pre-oedipal mother.

Fran's case showed her significant conflict throughout her marriage. Aside from the physical factors that prolonged her attempts to get pregnant, she also had unconsciously dis-identified with her mother for fear of repeating her mother's fruitfulness in procreation. Freud's repetition compulsion concept applies to these two cases in which the clinical phenomenon manifests with repetitive quality. However, analysis helped these two patients immensely with their aggressive conflicts as well as with the uncovering of their past trauma.

Freud cited four empirical observations as the basis for his theories and speculations: first, dreams occur in the traumatic 
neuroses in which patients repeat a traumatic situation. Second, there is a tendency on patients' part to repeat painful experiences from the past during their analyses. Third, the fate neuroses were an important notion. And fourth, certain types of children's play supports the concept of repetition.

In Moore and Fine's Psychoanalytic Terms and Concepts (1990), the meaning of the term "repetition compulsion" was extended to include drives for mastery as well as other adaptational and maturational processes. In Freud's speculations in Beyond the Pleasure Principle (1922), the repetition compulsion is presented as an explanatory concept, inextricably tied to the death instinct. It functions as a regulatory principle, primitive in its origin and mechanisms, biologically based, and capable of overriding the pleasure/un-pleasure principle. Kubie [14] stated that analysts after Freud have offered such diverse interpretations of the concept "as to render it almost meaningless" (p. 390).

Some contemporary authors believe that Freud's early concept of repetition compulsion is non-dynamic, negativistic and fatalistic; Lawrence B. Inderbitzin MD and Steven Levy, MD [15] (Psychoanalytic Quarterly. 67: 32-53 Repetition Compulsion Revisited: Implication for Technique).

There are many references to the repetition compulsion in psychoanalytic and psychiatric literature; I will list a selection that refers to the origin of the concept of compulsion to repeat and where it belongs in psychic structure.

Inderbitzin and Levy (1998) believe that one has to pay close attention to a more meaningful dynamic formulation, which includes a consideration of the intense frustration and ensuing aggression that trauma generates, and the opportunities for aggression provided by "re-experiencing trauma." Trauma appears to take on an instinctlike role that really belongs to the aggression created by the trauma. The re-experiences of trauma contain hidden aggressive aims and gratifications (often based on identification with the aggressor), including punishment of perpetrators by inducing guilt, demand for reparation, expression of entitlement, exploitation of others, magical "control" of helplessness, and purposeful self-defeat (self-directed aggression).

A woman's failure to conceive may be related to the traumatic and unsatisfactory relationship to her mother. The re-experience of trauma by repeated use of Assisted Reproductive Technology such as IVF, contains masked aggression, which is turned against self or others. The aggression may take the form of a demand for reparation and a magical solution to her age-induced infertility. Two clinical illustrations show how infertility traumata were re-experienced as a new version of an earlier trauma with self-induced traumatization through a compulsion to repeat.

\section{References}

1. Freud S (1940) An outline of psychoanalysis. S.E 23.

2. Deutsch H (1945) The Psychology of women. Grune and Stratton, Vol II, New York.

3. Benedek T (1952) Psychosocial Functions in Women. Ronald Press, New York.

4. Bibring G ET (1961) A study of psychological process in pregnancy and of the earliest mother and child relationship. Psychoanl Study Child 16: 9-72.
5. Notman M, Lester EP (1988) Pregnnacy: theoretical considerations. Psychoanl Inq 8: 139-160.

6. Pines D (1982) Relevance of early development to pregnancy and abortion. Int $J$ Psychoanal 61: 311-331.

7. Lester EP, Notman M (1986) Pregnancy, developmental crisis and object relations: Psychoanalytic considerations. Int J Psychoanal 62: 357-366.

8. Zalusky S (2000) Infertility in the age of technology. J Am Psychoanal Assoc 48: 1541-1562. [crossref]

9. Freud S (1923) The Ego and the Id. SE 19; 12-66.

10. Ehrensaft D (2008) When baby makes three or four or more, Psychanal. Study Child 63: 3-23.

11. Allison GH (1997) Motherhood, motherliness, and psychogenic infertility. Psychoanalytic Quarterly 66: 1-17.

12. Freud S (1914) Remembering, repeating and working-through. (Further recommendations on the technique of psycho-analysis II.) $S E 12$.

13. Freud S (1920) Beyond the pleasure principle. SE 18.

14. Kubie LS (1939) A critical analysis of the concept of a repetition compulsion. Int $J$ Psycho-Anal 20: 390-402.

15. Inderbitzin L B, Levy S (1998) Repetition Compulsion revisited: Implication for Technique, Psychoanalytic quarterly 67: 32-53.

\section{Citation:}

Mali Mann (2018) Psychoanalytic Understanding of Repeated In-Vitro Fertilization Trials, Failures, and Repetition Compulsion . Integr Gyn Obstet J Volume 1(2): 1-6. DOI: 10.31038/IGOJ.2018109 